\title{
Predictive Factors of Antidepressant Response and Remission to Bupropion Extended-Release or Psychosexual Therapy Among Infertile Women With Sexual Dysfunction
}

\author{
Hajar Pasha ${ }^{1}$, Zahra Basirat $^{1}$, Mahbobeh Faramarzi $^{2}$, Farzan Kheirkhah ${ }^{3^{*}}{ }^{\circledR}$, Soraya Khafri $^{4}$
}

\begin{abstract}
Objectives: This study aimed to evaluate the predictive factors of antidepressant response and remission to bupropion extendedrelease (BUP ER) or psychosexual therapy (PST) among infertile women with sexual dysfunction (SD).

Materials and Methods: As a randomized controlled clinical trial, this prospective study was carried out on 3 groups of BUP ER $(\mathrm{n}=31)$, PST $(\mathrm{n}=31)$, and control $(\mathrm{n}=31)$ in infertile women with SD in Babol, Iran during 2014-2015. Logistic regression was used to detect predictors of antidepressant response and remission.

Results: Antidepressant response and remission rates were $58.1 \%$ and $54.8 \%$ respectively in the PST group. Of the infertile women in the BUP group, $41.9 \%$ reached response and remission by the end of the study. The results for PST contained 2 predictors: occupation in response and remission (odds ratio $[\mathrm{OR}]=0.171, P=0.036 ; \mathrm{OR}=0.1, P=0.013$; respectively), and frequency of sexual intercourse in response $(\mathrm{OR}=0.124 ; P=0.040)$. The results for BUP contained three predictors: baseline severe depression level in remission $(\mathrm{OR}=0.044, P=0.010)$, economic status in response and remission $(\mathrm{OR}=5.850, P=0.027)$, and age difference of spouses in response $(P=0.031)$.

Conclusions: Depression screening and physician notification of demographic, reproductive and clinical predictors of antidepressant response and remission are necessary for selecting effective treatment interventions.

Keywords: Antidepressant, Psychotherapy, Bupropion, Response, Remission, Infertility, Predictor
\end{abstract}

\section{Introduction}

Infertility is described as a major crisis in life, which can significantly affect the psychological well-being of infertile women (1-3). Inability to conceive a child is associated with common mental consequences such as low self-efficacy, emotional burden, depression, and sexual problems (4-7). Studies show that infertile women are more likely to experience depression, and depression is considered as a prevalent sequel of infertility (2), which has an inverse effect on success of fertility $(8,9)$.

Pharmacological and non-pharmacological treatment options are used to improve depression (6). A review of the literature showed that psychological method was an effective therapy for depression (10), and was valuable for remission of depression $(11,12)$. Furthermore, bupropion (BUP) is an effective antidepressant drug (13). It acts as a supplemental treatment to reverse antidepressantincluded sexual dysfunction (SD), and increase sexual activity $(13,14)$. Studies showed that success rate in treating depression can be up to $50 \%-60 \%$ in psychotherapy or pharmacotherapy $(15,16)$, but numerous factors including socio-demographic characteristics of age, social support, economic status, being married, and family intervention could affect antidepressant response or remission $(17,18)$. Moreover, the role of clinical predictors of baseline depression levels, and duration of episodes in outcomes are important; all of which are inadequately understood $(19,21)$. In a review of predictors of depression, AkhtarDanesh and Landeen reported that age-predicted depression can affect resilient outcome (22). Another study revealed non-biological predictors of antidepressant response such as severe depression, long duration of episodes, duration of treatment, treatment dosage, severe inactivity, and overeating (23). Flynn et al reported that severity of depression can be considered as a significant predictor of depression treatment (24). Few studies have determined baseline depression levels as a moderator of depression outcomes between available treatment methods in infertility, to such an extent that some physicians rely on baseline symptoms to choose between initial drug therapy and other treatment methods. They suggest that checking medication and symptoms is a useful strategy 
$(25,26)$. Another study showed that patients' refractory to drugs may cause more severe levels of depression, which is associated with reduced response to treatment (27).

Perception of factors affecting response and remission to depression may lead to improved treatment in infertile women, and also choosing preferred treatment with attention to predictive factors may be a useful approach and may minimize non-effective treatment time. In the present study, we focused on predictors of antidepressant response and remission in infertile women with SD who received psychosexual therapy (PST) or BUP extendedrelease (BUP ER) treatment.

\section{Materials and Methods}

Study Design

This prospective randomized controlled clinical trial was conducted on infertile women referred to Fatemeh Zahra Infertility and Reproductive Health Research Center, Babol, Iran, from December 2014 to June 2015. The primary plan of this project was treatment of SD with subsequent improvement of depression symptoms. Inclusion criteria were the score $\leq 26.55$ in the Female Sexual Function Index (FSFI) and $\geq 10$ in Beck Depression Inventory (BDI), infertility for more than 1 year, being literate, $<45$ years of age, having no history of sterilization, not being remarried, and having no foster children. Subjects were excluded from the present study if they had the following conditions: history of seizure, previous suicide or suicide ideations, major depressive symptoms, experiencing a stressful event during the last 3 months, tobacco use, serious medical diseases, and taking drugs affecting seizure threshold or sexual function. Of the 485 infertile women, 127 refuted to participate, 129 had no SD, and 136 met exclusion criteria. Therefore, a total of 93 subjects with SD were randomly allocated into 3 groups: PST $(n=31)$, BUP $(n=31)$, and control $(n=31)$. For the PST group, treatment method was based on mindfulnessbased cognitive therapy (MBCT) (28), behavior sex therapy (29), and relaxation training (30), in a total of eight 2-hour group sessions. Each group consisted of 9-13 members. BUP ER was administered to BUP group at daily doses of $150 \mathrm{mg} / \mathrm{d}$ for 8 weeks. No psychological or pharmacological treatment was used for the control group.

\section{Data Collection}

Infertile women completed the Iranian-validated FSFI, a 19-item questionnaire for assessing female SD. Total score of FSFI ranges from 2 to 36 and higher score shows better sexual function. A score of less 26.55 was considered SD (7,31-33). Subjects also completed a translated and Persian-validated 21-item BDI at baseline and at the end of the study. An index score of $\leq 9$ was considered within normal range while a score of $10-18$ presented mild depression, a score of 19-29 pointed toward moderate depression, and a score $\geq 30$ showed severe depression.
The validity and reliability of BDI were 0.89 and 0.96 , respectively $(8,34,35)$. All subjects enrolled and randomly allocated to treatment were included in the intention- totreat analysis.

\section{Data Analysis}

The frequency of antidepressant response and remission outcomes was obtained in the groups. A reduction $\geq 50 \%$ in the baseline depression score was defined as response, and obtaining final BDI score $\leq 9$ was considered as remission $(25,36,37)$. The clinical, demographic, and reproductive variables were evaluated as possible predictors of antidepressant response and remission to PST or BUP ER. To detect predictors of antidepressant response and remission, first, the association of antidepressant response and remission with clinical, demographic, and reproductive factors was evaluated using $\chi^{2}$ test. Then, to predict the association of independent variables (clinical, demographic, and reproductive characteristics) with dependent variables (antidepressant response, antidepressant remission), when $P$ value was $<0.1$, independent variables were entered into multiple logistic regression. Age, husband's age, couples' age difference, housing, current settlement type, occupation, husband's occupation, economic status, education status, and husband's education were considered as demographic variables. Reproductive factors included infertility type, infertility cause, infertility duration, marriage duration, and frequency of sexual intercourse per week. The clinical predictors were the severity of depression at baseline, and female sexual function. Data were analyzed using SPSS software, version 21.0.

\section{Results}

The mean age of infertile women and men was $29 \pm 5.44$ and $32.33 \pm 5.31$ years, respectively. Most of the infertile women lived in urban areas and had diploma level of education. The duration of infertility in most infertile women was $<5$ years. The cause of infertility in nearly one-third of infertile women was reported to be a male factor. Table 1 shows the characteristics of the subjects. The demographic characteristics were similar in the 3 groups.

Antidepressant response and remission rates were 58.1\% and $54.8 \%$ respectively in the PST group. Of the infertile women in BUP group, $41.9 \%$ reached response and also remission in the end of the study (Figure 1). There was a significant association between antidepressant remission and severity of depression symptoms in the BUP group $\left(\chi^{2}=9.703, P=0.008\right)$. Higher baseline Beck depression levels indicated a lower remission rate in BUP users (Figure 2). Clinical predictor of depression severity at baseline was associated with antidepressant remission in the BUP users. The logistic regression showed that among BUP users, those with severe depression were 0.044 times less likely to remit compared with those with mild 
Table 1. Demographic Features of Infertile Women With Sexual Dysfunction

\begin{tabular}{|c|c|c|c|c|c|}
\hline \multirow{2}{*}{ Variable $^{a}$} & \multicolumn{2}{|c|}{ Treatment Groups } & \multirow{2}{*}{ Control $(n=31)$} & \multirow{2}{*}{ Total $(n=93)$} & \multirow{2}{*}{$P$ Value } \\
\hline & PST $(n=31)$ & BUP ER $(n=31)$ & & & \\
\hline Women's age (y) & $30.26 \pm 5.31$ & $27.58 \pm 5.26$ & $29.16 \pm 5.57$ & $29 \pm 5.44$ & 0.150 \\
\hline Men's age (y) & $33.32 \pm 5.85$ & $30.87 \pm 3.69$ & $32.81 \pm 5.92$ & $32.33 \pm 5.31$ & 0.160 \\
\hline Couples' age difference (y) & $3.06 \pm 4.79$ & $3.29 \pm 4.02$ & $3.64 \pm 4.63$ & $3.33 \pm 4.45$ & 0.877 \\
\hline Marriage duration (y) & $7.71 \pm 4.52$ & $6.87 \pm 3.77$ & $6.68 \pm 4.45$ & $7.09 \pm 4.24$ & 0.600 \\
\hline Current settlement type & & & & & 0.739 \\
\hline Urban & $15(16.1)$ & $16(17.2)$ & $18(19.4)$ & $49(52.7)$ & \\
\hline Rural & $16(17.2)$ & $15(16.1)$ & $13(14)$ & $44(47.3)$ & \\
\hline Educational status & & & & & 0.390 \\
\hline Primary & $3(3.2)$ & $3(3.2)$ & $0(0)$ & $6(6.5)$ & \\
\hline High school & $6(6.5)$ & $7(7.5)$ & $4(4.3)$ & $17(18.3)$ & \\
\hline Diploma & $15(16.1)$ & $15(16.1)$ & $15(16.1)$ & $45(48.4)$ & \\
\hline University & $7(7.5)$ & $6(6.5)$ & $12(12.9)$ & $25(26.9)$ & \\
\hline Husband educational status & & & & & 0.811 \\
\hline Primary & $3(3.2)$ & $4(4.3)$ & $4(4.3)$ & $11(11.8)$ & \\
\hline High school & $8(8.6)$ & $8(8.6)$ & $7(7.5)$ & $23(24.7)$ & \\
\hline Diploma & $13(14)$ & $9(9.7)$ & $8(8.6)$ & $30(32.3)$ & \\
\hline University & $7(7.5)$ & $10(10.8)$ & $12(12.9)$ & $29(31.2)$ & \\
\hline Infertility cause & & & & & 0.806 \\
\hline Female factor & $2(2.2)$ & $2(2.2)$ & $5(5.4)$ & $9(9.7)$ & \\
\hline Male factor & $11(11.8)$ & $11(11.8)$ & $9(9.7)$ & $31(33.3)$ & \\
\hline Causes of female and male & $9(9.7)$ & $10(10.8)$ & $7(7.5)$ & $26(28)$ & \\
\hline Unexplained factors & $9(9.7)$ & $8(8.6)$ & $10(10.8)$ & $27(29)$ & \\
\hline Infertility duration (y) & & & & & 0.395 \\
\hline$<5$ & 25 (26.9) & $19(20.4)$ & $23(24.7)$ & $67(72)$ & \\
\hline $6-10$ & $3(3.2)$ & $9(9.7)$ & $6(6.5)$ & $18(19.4)$ & \\
\hline$\geq 11$ & $3(3.2)$ & $3(3.2)$ & $2(2.2)$ & $8(8.6)$ & \\
\hline
\end{tabular}

Abbreviations: PST, psychosexual therapy; BUP, bupropion extended-release.

a Values are mean \pm standard deviation or number (\%).

depression (odds ratio $[\mathrm{OR}]=0.044, P=0.010$ ). Moreover, there was no significant association between pretreatment depression levels and antidepressant remission in the PST group. As presented in Table 2, using binary logistic regression did not reveal a significant association between baseline depression levels and antidepressant response in each of the groups (Tables 2 and 3).

Applying chi-square test revealed a significant

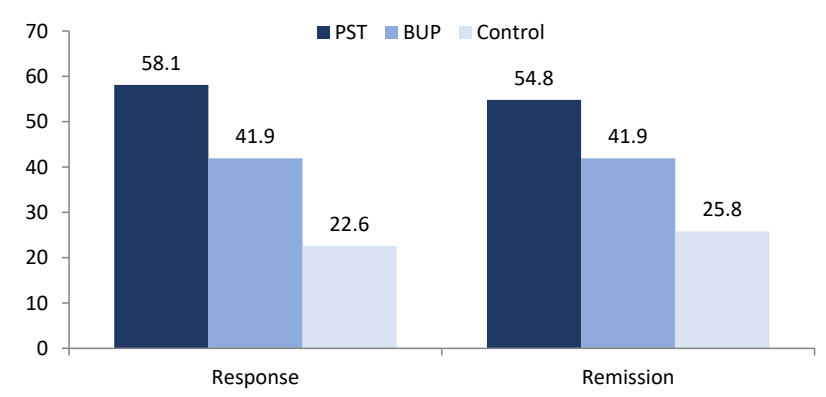

Figure 1. The Response ${ }^{a}$ and Remission ${ }^{b}$ Rate in 3 Study Groups. Abbreviations: PST, psychosexual therapy; BUP, bupropion extendedrelease.

${ }^{\text {a }}$ Considered as a reduction $\geq 50 \%$ in baseline BDI score.

b Considered as final BDI score $\leq 9$.

Values are shown as percentage.

$n=93$ (each group of 31 participants). association between demographic variables of occupation and antidepressant response $\left(\chi^{2}=4.775, P=0.029\right)$ or remission $\left(\chi^{2}=7.235, P=0.007\right)$ in the PST group. The chance of antidepressant response in the employed women was 0.171 -fold less than that in the housekeeper women in the PST group $(\mathrm{OR}=0.171, P=0.036)$. Furthermore, the chance of antidepressant remission in the employed women was 0.1 -fold less than that in the housekeeper women in the PST group $(\mathrm{OR}=0.100, P=0.013)$. There was an association between the demographic variables of economic status and antidepressant response $\left(\chi^{2}=5.237\right.$, $P=0.022)$ and remission $\left(\chi^{2}=5.237, P=0.022\right)$ in the BUP group. Subjects with low economic status had less antidepressant response or remission than those who had moderate/high economic status $(30.8 \%$ vs. $69.2 \%)$. The chance of antidepressant response and remission in the women with moderate/good economic status was 5.850fold more than that in the women with poor economic status in the BUP group $(\mathrm{OR}=5.850, P=0.027)$.

There was a significant difference in the mean of couples' age difference between respondents and nonrespondents in the BUP group $(\mathrm{t}=-2.271, P=0.031)$. The mean of couples' age difference in the respondents was 5.077 (3.593), and in non-respondents was 2 (3.895) in the BUP group. For each year, an increase in the couples' 

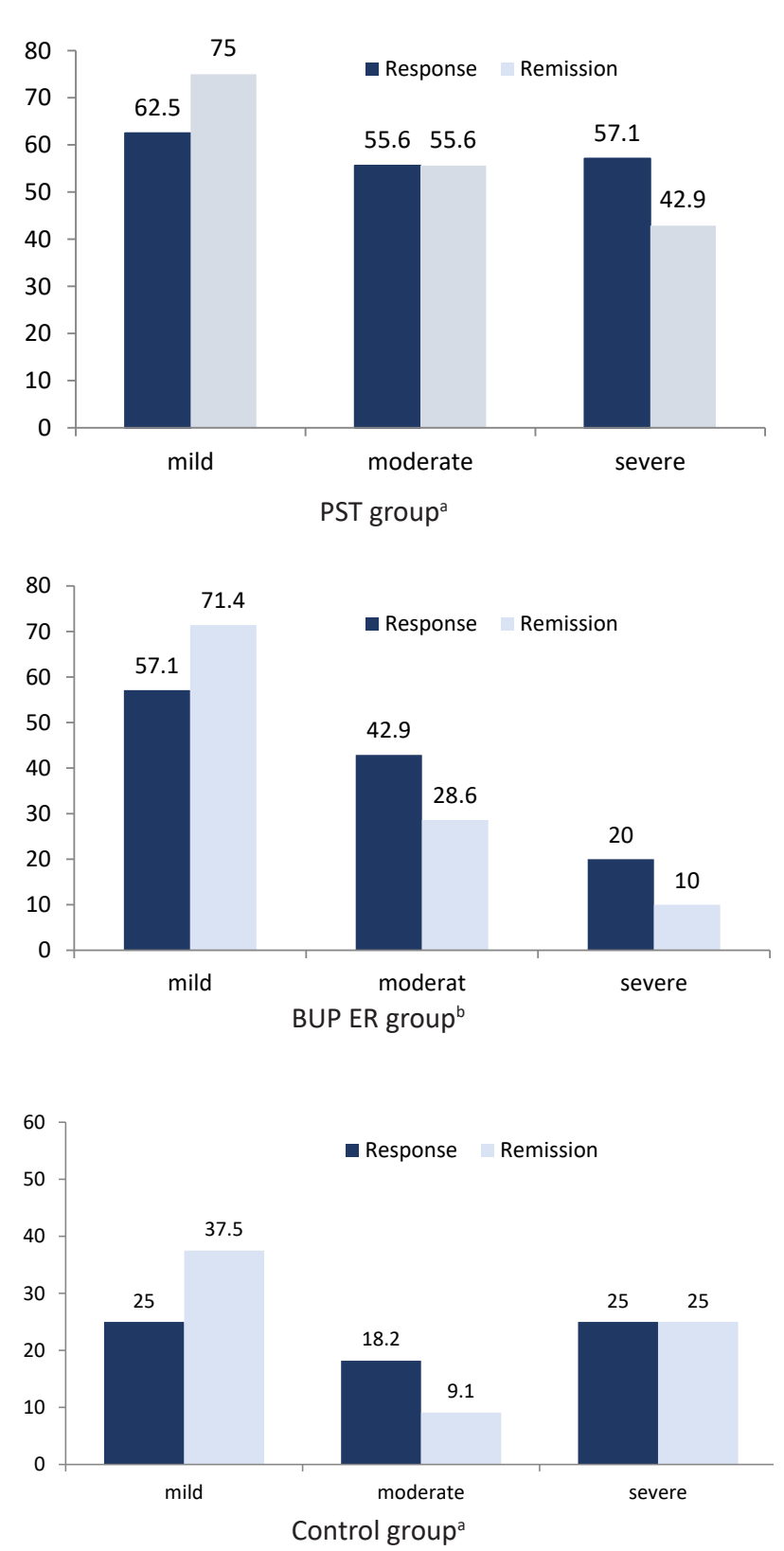

Figure 2. The Association of Antidepressant Response ${ }^{\mathrm{a}}$ and Remission ${ }^{b}$ With Pretreatment Depression Levels (Mild, Moderate, and Severe) in Each Group

Note: PST, psychosexual therapy; BUP ER, bupropion extendedrelease. $n=93$ (each group of 31 participants).

Response (PST group, $P=0.955$; BUP group, $P=0.191$; Control group, $P=0.910)$

Remission (PST group, $P=0.345$; BUP group, $P=0.008$; Control group, $P=0.253$ )

$\mathrm{X}^{2}$ test used for data analysis.

age difference, the odds of response increased by $32.4 \%$ in the BUP group $(\mathrm{OR}=1.263)$. There were no predictive reproductive factor of antidepressant response or remission in each group (Tables 2 and 3 ).

After adjusting for other variables, occupation $(\mathrm{OR}=0.081, \quad P=0.021)$ and frequency of sexual intercourse $(\mathrm{OR}=0.124, P=0.040)$ were predictors of antidepressant response in the PST group. Moreover, the variable of occupation $(\mathrm{OR}=0.023, \quad P=0.012)$ predicted antidepressant remission rate in the PST group. There was a trend for reported couples' age difference $(\mathrm{OR}=0.719, P=0.056)$ in the PST group, and economic status $(\mathrm{OR}=5.123, P=0.057)$ in the BUP group to remain predictive for antidepressant remission.

\section{Discussion}

The main goal of this study was to detect predictors of antidepressant response or remission to BUP ER or PST among infertile women with SD during an 8-week randomized controlled clinical trial.

Our first aim was to evaluate the clinical predictors of antidepressant response and remission. The results revealed that depression baseline level had a significant preventive effect on antidepressant remission in the BUP group. On the other hand, our findings indicated that higher baseline Beck depression score was associated with slightly lower remission rates for BUP users. The pretreatment depression levels could only predict whether BUP users are remitted or unremitted, while there was no association between antidepressant response and baseline severity depression in the BUP group. These results are similar to the reports of Rush et al that represented a failure in detecting association between pretreatment levels in major depressive disturbance and response to BUP (25). In a similar study, there was an inverse association between remission and severity at baseline from BUP treatment (26). Rush et al reported that some physicians attend to pretreatment symptoms to decide the initial medication (25). Other studies revealed that the patients resistant to drugs or other therapies may have more severe levels of depression; this is associated with reduced remission to the treatment $(27,36)$.

The second goal of the present study was to assess the demographic predictors of response and remission outcomes in each group. The results of this study showed that the employed women reached antidepressant response or remission at a lower rate compared with those with housekeeping jobs in the PST group, even after adjusting for other variables. Park et al showed that occupational stress may increase the risk of depressive symptoms (38), as occupation is one of the effective factors in describing the changeability of depression rate. It is expected that the response and remission rates in the employed women are fewer than that in the unemployed patients.

Our findings revealed that only economic status strongly predicted antidepressant response or remission in BUP. It is interesting to note that the BUP users with good/ moderate income were 5.5 times more likely to remit or respond than the patients with low income. HasanpoorAzghdy et al in a quality study reported that many infertile women were worried following the treatment because of spending a lot of money, especially when the result of treatment was negative (39). Women with low income are under more pressure because of treatment expenses. A review of the literature revealed that socio-demographic 
Table 2. Demographic and Clinical Predictors of Antidepressant Response in 3 Study Groups

\begin{tabular}{|c|c|c|c|}
\hline \multirow{2}{*}{ Variable } & PST Group & BUP Group & Control Group \\
\hline & OR (Cl95\%) & OR (Cl95\%) & OR (Cl95\%) \\
\hline \multicolumn{4}{|c|}{ Demographic Predictors } \\
\hline \multicolumn{4}{|l|}{ Occupation } \\
\hline Housekeeper & 1.0 (Ref) & 1.0 (Ref) & 1.0 (Ref) \\
\hline Employee & $0.171(.033-.893)^{\mathrm{a}}$ & 1.455 (0.177-11.937) & $0.633(.061-6.542)$ \\
\hline \multicolumn{4}{|c|}{ Frequency of sexual intercourse } \\
\hline$<3$ times per week & 1.0 (Ref) & 1.0 (Ref) & 1.0 (Ref) \\
\hline$\geq 3$ times per week & $0.245(0.052-1.162)^{b}$ & $1.156(0.241-5.530)$ & $1.821(0.321-10.342)$ \\
\hline \multicolumn{4}{|l|}{ Economic status } \\
\hline Low & 1.0 (Ref) & 1.0(Ref) & 1.0 (Ref) \\
\hline Moderate/high & $1.156(0.241-5.530)$ & $5.850(1.222-27.994)^{c}$ & $0.549(0.097-3.117)$ \\
\hline Couples' age difference (y) & $0.969(0.832-1.129)$ & $1.263(0.998-1.597)^{d}$ & $0.906(0.744-1.104)$ \\
\hline \multicolumn{4}{|c|}{ Clinical Predictors } \\
\hline \multicolumn{4}{|c|}{ Baseline depression symptom at baseline } \\
\hline Mild & 1.0 (Ref) & 1.0 (Ref) & 1.0 (Ref) \\
\hline Moderate & $0.75(0.11-5.24)$ & $0.56(0.09-3.52)$ & $0.67(0.1-4.48)$ \\
\hline Severe & $0.80(0.14-4.75)$ & $0.19(0.03-1.23)$ & $1.00(0.08-12.56)$ \\
\hline Female sexual function & $1.146(0.868-1.515)$ & $1.1443(0.947-2.200)$ & $1.310(0.823-2.085)$ \\
\hline
\end{tabular}

Abbreviations: PST, psychosexual therapy; BUP ER, bupropion extended-release.

Response considered as a reduction $\geq 50 \%$ in baseline BDI score.

Remission considered as final BDI score $\leq 9$.

$\mathrm{n}=93$ (each group of 31 participants).

Mild depression is used as reference category.

Binary and multiple logistic regression was applied for data analysis.

a $P=0.036$, after adjusting other variables $P=0.02 ;{ }^{\text {b }} P=0.04$ after adjusting other variables; ${ }^{\mathrm{c}} P=0.027,{ }^{\mathrm{d}} P=.052$.

Table 3. Demographic and Clinical Predictors of Antidepressant Remission in 3 Study Groups

\begin{tabular}{|c|c|c|c|}
\hline \multirow{2}{*}{ Variable } & PST Group & BUP Group & Control Group \\
\hline & OR (Cl95\%) & OR (CI95\%) & OR (CI95\%) \\
\hline \multicolumn{4}{|c|}{ Demographic Predictors } \\
\hline \multicolumn{4}{|l|}{ Occupation } \\
\hline Housekeeper & 1.0 (Ref) & 1.0 (Ref) & 1.0 (Ref) \\
\hline Employee & $0.1(0.016-0.615)^{\mathrm{a}}$ & $1.455(0.177-11.937)$ & $1.583(0.230-10.904)$ \\
\hline \multicolumn{4}{|l|}{ Economic status } \\
\hline Low & 1.0 (Ref) & 1.0 (Ref) & 1.0 (Ref) \\
\hline Moderate/high & $0.960(0.202-4.567)$ & $5.850(1.222-27.994)^{b}$ & $0.729(0.135-3.930)$ \\
\hline Couples' age difference (y) & $0.844(0.701-1.016)^{c}$ & $1.124(0.926-1.365)$ & $1.007(0.844-1.201)$ \\
\hline \multicolumn{4}{|c|}{ Clinical Predictors } \\
\hline \multicolumn{4}{|c|}{ Baseline depression symptom at baseline } \\
\hline Mild & 1.0 (Ref) & 1.0 (Ref) & 1.0 (Ref) \\
\hline Moderate & $0.42(0.05-3.31)$ & $0.16(0.02-1.19)$ & $0.17(0.02-1.65)$ \\
\hline Severe & $0.25(0.04-1.70)$ & $0.04(0.004-0.48)^{d}$ & $0.56(0.05-6.63)$ \\
\hline Female sexual function & $1.136(0.862-1.497)$ & $1.144(0.947-2.20)$ & $1.358(0.863-2.137)$ \\
\hline
\end{tabular}

Abbreviations: PST, psychosexual therapy; BUP ER, bupropion extended-release.

Response considered as a reduction $\geq 50 \%$ in baseline BDI score.

Remission considered as final BDI score $\leq 9$.

$\mathrm{n}=93$ (each group of 31 participants).

Mild depression is used as reference category.

Binary and multiple logistic regression was applied for data analysis.

${ }^{\mathrm{a}} P=0.013, P=0.01$ after adjusting other variables; ${ }^{\mathrm{b}} P=0.027, P=0.057$ after adjusting other variables, ${ }^{\mathrm{c}} P=0.057$ after adjusting other variables; ${ }^{\mathrm{d}}$ $P=0.01$. 
characteristics such as income are important factors in depression. The depression rate decreases with increased income (22). Another study showed social support as a positive predictor of antidepressant response (17-18). It appears that having a good income can associate with higher social support and more flexibility to antidepressant treatment, which may play an important role in response and remission to depression symptoms.

The present study showed a trend of the couples' age difference to remain as a predictor factor in antidepressant remission in the PST group after adjusting for other variables, and also with an antidepressant response in the BUP group. Women with higher age differences with their spouses were less likely to remit or respond than those with lower age differences with their spouses. Rahmani et al reported a significant relationship between the couples' age difference and marital satisfaction. Women who had a lower age difference with their spouses were more satisfied with marital life (40); this can affect decreased depression and, more likely, antidepressant response or remission. Therefore, it is important to pay attention to age differences in the marriage.

The third goal was to assess reproductive predictors of response and remission outcomes in each group. After adjusting for other variables, the frequency of sexual intercourse was the predictor of antidepressant response in the PST group. Women who had sexual intercourse $\geq 3$ times a week had less chance to respond than those with sexual intercourse $<3$ times a week. Basically, there is a biological reason why people have sex twice a week. Hall et al reported that ratio of sexual activity in a week was higher in the depressed women than in those who had no depression symptoms (41). The study showed that sexual experience may display an attempt to control emotions or request support. Patients used sex to improve and relieve their depression. This suggests that depressive symptoms can predict sexual activity. Depressive symptoms were associated with increased frequency of sexual intercourse, which may impair quality of romantic and sexual experience (42). When sex goes beyond the usual, it reduces the feeling of joy and being romantic in a sexual relationship. Thus, it can lead to increased severity of depression and resistance to antidepressant treatment.

\section{Conclusions}

Predictors of antidepressant response, as well as remission to PST or BUP ER among infertile women suffering from SD were presented in this investigation. It was found that the demographic together with clinical predictors play a significant role in antidepressant response and remission. As a result, it is strongly recommended to consider these factors while planning treatment interventions.

\section{Limitations and Strengths}

Several potential limitations and strengths were found in this study. First, the results of this research cannot be generalized to other antidepressant medications or psychosexual therapies beyond those studied in this investigation. Secondly, contribution of major depression matters was excluded from this study; therefore, the presented outcomes cannot be employed to the cases of infertile women with major depression or suicidal thoughts. In addition, the results of our analyses originated from a clinical trial study; thus, it might not be capable of taking a broad view of the routine clinical techniques. Finally, the use of valuable valid Iranian version of FSFI and BDI questionnaires in this research was a strength.

\section{Conflict of Interests}

Authors declare that there is no conflict of interests.

\section{Ethical Issues}

The study was approved by the Ethics Committee of Babol University of Medical Sciences, Iran (code of ethics: 4930, 10/12/2014), with IRCT registration number IRCT2015042721955N2. After explaining the procedures, all participants provided informed consent.

\section{Acknowledgements}

The authors would like to thank Babol University of Medical Sciences, Iran, which supported the preparation of this project. We sincerely appreciate all the patients for contributing in the study and Dr. Evangeline Foronda $(\mathrm{PhD})$ for the English editing of the paper.

\section{Financial Support}

Babol University of Medical Sciences, Iran.

\section{References}

1. Sehhatie Shafaie F, Mirghafourvand M, Rahimi M. Perceived Stress and its Social-Individual Predictors among Infertile Couples Referring to Infertility Center of Alzahra Hospital in Tabriz in 2013. Int J Womens Health Reprod Sci. 2014;2(5):291-296. doi:10.15296/ijwhr.2014.47

2. Pasha H. Evaluation of Depression in Infertile Women Using Beck and Hamilton. Int J Fertil Steril. 2011;5(Suppl 1).

3. Pasha H, Basirat Z, Faramarzi M, Kheirkhah F. Pharmacological and Non-pharmacological Therapeutic Strategies for Improvement of State-Trait Anxiety: A Randomized Controlled Trial Among Iranian Infertile Women With Sexual Dysfunctions. Crescent Journal of Medical and Biological Sciences. 2017;4(2):47-53.

4. Fassino S, Piero A, Boggio S, Piccioni V, Garzaro L. Anxiety, depression and anger suppression in infertile couples: a controlled study. Hum Reprod. 2002;17(11):2986-2994.

5. Pasha H, Faramarzi M, Esmailzadeh S, Kheirkhah F, Salmalian H. Comparison of pharmacological and nonpharmacological treatment strategies in promotion of infertility self-efficacy scale in infertile women: A randomized controlled trial. Iran J Reprod Med. 2013;11(6):495-502.

6. Faramarzi M, Alipor A, Esmaelzadeh S, Kheirkhah F, Poladi $\mathrm{K}$, Pash $\mathrm{H}$. Treatment of depression and anxiety in infertile 
women: cognitive behavioral therapy versus fluoxetine. J Affect Disord. 2008;108(1-2):159-164. doi:10.1016/j. jad.2007.09.002

7. Basirat Z, Pasha H, Esmailzadeh S, Faramarzi M. Evaluation of the Female Sexual Dysfunction in a Sample of Iranian Infertile Women. Br J Med Med Res. 2014;4(36):5825-5838. doi:10.9734/BJMMR/2014/11737

8. Noorbala AA, Ramazanzadeh F, Malekafzali H, et al. Effects of a psychological intervention on depression in infertile couples. Int J Gynaecol Obstet. 2008;101(3):248-252. doi:10.1016/j.ijgo.2007.12.010

9. Ramezanzadeh F, Noorbala AA, Abedinia N, Rahimi Forooshani A, Naghizadeh MM. Psychiatric intervention improved pregnancy rates in infertile couples. Malays J Med Sci. 2011;18(1):16-24.

10. Hansson M, Bodlund O, Chotai J. Patient education and group counselling to improve the treatment of depression in primary care: a randomized controlled trial. J Affect Disord. 2008;105(1-3):235-240. doi:10.1016/j.jad.2007.04.007

11. National Collaborating Centre for Mental H. National Institute for Health and Clinical Excellence: Guidance. Depression: The Treatment and Management of Depression in Adults. Leicester (UK): British Psychological Society; 2010.

12. Bandelow B, Sher L, Bunevicius R, et al. Guidelines for the pharmacological treatment of anxiety disorders, obsessivecompulsive disorder and posttraumatic stress disorder in primary care. Int J Psychiatry Clin Pract. 2012;16(2):77-84. doi:10.3109/13651501.2012.667114

13. Fava M, Rush AJ, Thase ME, et al. 15 years of clinical experience with bupropion $\mathrm{HCl}$ : from bupropion to bupropion SR to bupropion XL. Prim Care Companion J Clin Psychiatry. 2005;7(3):106-113.

14. Clayton AH, Warnock JK, Kornstein SG, Pinkerton R, Sheldon-Keller A, McGarvey EL. A placebo-controlled trial of bupropion SR as an antidote for selective serotonin reuptake inhibitor-induced sexual dysfunction. J Clin Psychiatry. 2004;65(1):62-67.

15. Iovieno N, Tedeschini E, Ameral VE, Rigatelli M, Papakostas GI. Antidepressants for major depressive disorder in patients with a co-morbid axis-III disorder: a meta-analysis of patient characteristics and placebo response rates in randomized controlled trials. Int Clin Psychopharmacol. 2011;26(2):69-74. doi:10.1097/YIC.0b013e328340775e

16. Cuijpers P, Karyotaki E, Weitz E, Andersson G, Hollon $\mathrm{SD}$, van Straten A. The effects of psychotherapies for major depression in adults on remission, recovery and improvement: a meta-analysis. J Affect Disord. 2014;159:118-126. doi:10.1016/j.jad.2014.02.026

17. Trivedi MH, Morris DW, Pan JY, Grannemann BD, John Rush A. What moderator characteristics are associated with better prognosis for depression? Neuropsychiatr Dis Treat. 2005;1(1):51-57.

18. Tomaszewska W, Peselow ED, Barouche F, Fieve RR. Antecedent life events, social supports and response to antidepressants in depressed patients. Acta Psychiatr Scand. 1996;94(5):352-357.

19. Layne AE, Bernstein GA, Egan EA, Kushner MG. Predictors of treatment response in anxious-depressed adolescents with school refusal. J Am Acad Child Adolesc Psychiatry.
2003;42(3):319-326_ doi:10.1097/00004583-20030300000012

20. Kowatch RA, Carmody TJ, Emslie GJ, Rintelmann JW, Hughes CW, Rush AJ. Prediction of response to fluoxetine and placebo in children and adolescents with major depression: a hypothesis generating study. J Affect Disord. 1999;54(3):269-276.

21. Emslie GJ, Mayes TL, Laptook RS, Batt M. Predictors of response to treatment in children and adolescents with mood disorders. Psychiatr Clin North Am. 2003;26(2):435456.

22. Akhtar-Danesh N, Landeen J. Relation between depression and sociodemographic factors. Int J Ment Health Syst. 2007;1(1):4. doi:10.1186/1752-4458-1-4

23. Aliapoulous J, Zisook S. Tricyclic antidepressants medications. In: Goodnick PJ, ed. Predictors of treatment response in mood disorders. Washington: American Psychiatric; 1996.

24. Flynn HA, Blow FC, Marcus SM. Rates and predictors of depression treatment among pregnant women in hospital-affiliated obstetrics practices. Gen Hosp Psychiatry. 2006;28(4):289-295. doi:10.1016/j. genhosppsych.2006.04.002

25. Rush AJ, Trivedi MH, Carmody TJ, et al. Response in relation to baseline anxiety levels in major depressive disorder treated with bupropion sustained release or sertraline. Neuropsychopharmacology. 2001;25(1):131138. doi:10.1016/s0893-133x(00)00249-9

26. Rush AJ, Batey SR, Donahue RM, Ascher JA, Carmody TJ, Metz A. Does pretreatment anxiety predict response to either bupropion SR or sertraline? J Affect Disord. 2001;64(1):81-87.

27. Fregni F, Marcolin MA, Myczkowski M, et al. Predictors of antidepressant response in clinical trials of transcranial magnetic stimulation. Int J Neuropsychopharmacol. 2006;9(6):641-654. doi:10.1017/s1461145705006280

28. Mohammadkhani P, Tamannaiy-Far S, Ahanie-Tabedh O. Mindfulness-Based Cognitive Therapy for Depression: A New Approach to Preventing Relapse.1st ed. Tehran: Faradid Publication; 2005.

29. Crowe M, Ridley J. Therapy with Couples: A BehavioralSystems Approach to Couple Relationship and Sexual Problems. Oxford: Wiley-Blackwell; 2000.

30. Bahadoran K, Pournaseh M. A path to tranquality, Mindfulness and Medication. Tehran (Iran): Mehr Kavian; 2009.

31. Rosen R, Brown C, Heiman J, et al. The Female Sexual Function Index (FSFI): a multidimensional selfreport instrument for the assessment of female sexual function. J Sex Marital Ther. 2000;26(2):191-208. doi:10.1080/009262300278597

32. Safarinejad MR. Female sexual dysfunction in a populationbased study in Iran: prevalence and associated risk factors. Int J Impot Res. 2006;18(4):382-395. doi:10.1038/ sj.ijir. 3901440

33. Fakhri A, Pakpour AH, Burri A, Morshedi H, Zeidi IM. The Female Sexual Function Index: translation and validation of an Iranian version. J Sex Med. 2012;9(2):514-523. doi:10.1111/j.1743-6109.2011.02553.x

34. Beck AT, Steer RA, Carbin MG. Psychometric properties 
of the Beck Depression Inventory: Twenty-five years of evaluation. Clin Psychol Rev. 1988;8(1):77-100. doi:10.1016/0272-7358(88)90050-5

35. Beck AT, Rush AJ, Shaw BF, Emery G. Cognitive therapy of depression: A treatment manual. New York: Guilford Press; 1979.

36. Grammer GG, Kuhle AR, Clark CC, Dretsch MN, Williams KA, Cole JT. Severity of Depression Predicts Remission Rates Using Transcranial Magnetic Stimulation. Front Psychiatry. 2015;6:114. doi:10.3389/fpsyt.2015.00114

37. Weitz ES, Hollon SD, Twisk J, et al. Baseline Depression Severity as Moderator of Depression Outcomes Between Cognitive Behavioral Therapy vs Pharmacotherapy: An Individual Patient Data Meta-analysis. JAMA Psychiatry. 2015;72(11):1102-1109. doi:10.1001/ jamapsychiatry.2015.1516

38. Park SG, Min KB, Chang SJ, Kim HC, Min JY. Job stress and depressive symptoms among Korean employees: the effects of culture on work. Int Arch Occup Environ Health. 2009;82(3):397-405. doi:10.1007/s00420-008-0347-8

39. Hasanpoor-Azghdy SB, Simbar M, Vedadhir A. The emotional-psychological consequences of infertility among infertile women seeking treatment: Results of a qualitative study. Iran J Reprod Med. 2014;12(2):131-138.

40. Rahmani A, Merghati Khoei E, Alah Gholi L. Sexual Satisfaction and its Relation to Marital Happiness in Iranians. Iran J Public Health. 2009;38(4):77-82.

41. Hall KS, Kusunoki Y, Gatny H, Barber J. Stress symptoms and frequency of sexual intercourse among young women. J Sex Med. 2014;11(8):1982-1990. doi:10.1111/jsm.12607

42. Richards CS, O'Hara MW. The Oxford Handbook of Depression and Comorbidity. New York: Oxford University Press; 2014.

(C) 2018 The Author (s); This is an open-access article distributed under the terms of the Creative Commons Attribution License (http://creativecommons.org/licenses/by/4.0), which permits unrestricted use, distribution, and reproduction in any medium, provided the original work is properly cited. 